Original article

\title{
Internet addiction among students of Islamic Azad University
}

\author{
Ramzan Hasanzadeh ${ }^{1}$, Ghahraman Mahmoodi ${ }^{2}$, Masoumeh Bagheri-Nesami ${ }^{3}$, Jabbar Heydari Fard ${ }^{4, *}$
}

(Received: 9 Aug 2014; Accepted 7 sep 2014)

\begin{abstract}
Background and Purpose: Today, the increasing demand of computer technology \& the vast internet technology penetration despite its plentiful benefits has exposed most people especially college goers to disorder in their psychological health \& social communications due to being afflicted to computer addiction. Thus regarding the contradictory results of the studies conducted in this field, the present research has been done with the goal to investigate the Internet Addiction (IA) level in Sari Islamic Azad University students in 2013.

Methods: In the present research, the descriptive method has been applied . The statistical community consists of all students of Islamic Azad University located in Sari in 2013. Out of the statistical community, based on sample size determination table from the community size or korjesi-Morgan table, 261 individuals have been selected by random stratified sampling. To collect data, a two-part questionnaire of demographic characteristics \& IA test have been applied. To analyze data, descriptive -inferential statistics such as ANOVA \& independent thave been employed by SPSS software.

Results: According to the study findings, the students' mean age \& standard deviation have been $24.3 \pm 3.7$. 17.6\% of the students have been included in average to severe IA range. The internet addiction in various ages has been meaningful among the students. Among girl \& boy students, IA is meaningful at $\mathrm{P}=0.05$. Based on the students using the internet, IA is significant at $\mathrm{P}=0.05$.

Conclusion: According to the present research findings, the internet addiction is common among the students and in order to prevent its dangers \& complications in the students, it seems necessary to pay attention to the health $\&$ therapeutic considerations.
\end{abstract}

Keywords: Mental health, Internet addiction, Students

\section{Introduction}

Various uses of the internet $\&$ its attractions in the recent years have resulted in the emergence of a phenomenon known as the Internet Addiction (IA). The internet addiction is defined with expressions like the disorder out of using the internet too much or using it in an irrational or morbidful manner and or sometimes termed as the Internet Addiction Disorder or Virtual Addiction. Accessing the internet is a growing trend \& every day, more individuals are added as the internet users. The internet is present everywhere including houses, schools and shopping centers. Goldberg used the term the Internet Addiction Disorder for the first time (1) to introduce \& identify the features of those displaying disorders following the use of the internet. He was the first who formed an internet addicts' support group (2). The internet addiction physical \& mental dependency is similar to that of substance addicts (3). Most of the internet users are the youth and averagely speaking, they spend

\footnotetext{
${ }^{1}$ Department of Psychology, Islamic Azad University, Sari- Branch, Iran.

${ }^{2}$ Department of Nursing, Azad University, Sari- Branch, Iran.

${ }^{3}$ Traditional and Complementary Medicine Research Centre, Department of Medical Surgical Nursing, Nasibeh Nursing \& Midwifery School, Mazandran University of Medical Sciences, Sari, Iran.

${ }^{4, *}$ Corresponding author: Department of Psychiatric Nursing, Nasibeh Nursing \& Midwifery School, Mazandran University of Medical Sciences, Sari, Iran. EMail: heydari347@yahoo.com.
} 
0.035 of their time on chartrooms, 0.028 on games, 0.025 on browsing the web pages $\& 0.030$ on e-mail(4). The internet has changed our daily life dramatically as a very important communication medium in the house, the educational setting \& work place (3). Computer $\&$ its widespread penetration in the modern world has caused everybody to get involved and deal with this technology in a way. This increasing demand for the internet technology has brought about serious mental health \& unhealthy social communication nuisances (5). The issue as excessive \& pathological use of this technology \& IA has drawn the psychologists' \& the other researchers' attention to itself (6).

Yellowlees et al. reported contradictory reports on the internet addiction (7). Also the other researchers have pointed out that excessive use of the internet has left an adverse effect on the students' mental health. These researchers noted that the students using the internet excessively \& pathologically displayed more mental problems \& pathology compared with those not experiencing such a phenomenon $(8,9)$.

In fact, the increase in experience levels working with the internet is associated with reduced mental health level. IA has influenced a wide range of the individuals directly and indirectly. Studying a number of the individuals under the direct or indirect influence of this phenomenon, it is possible to understand its extent level $(9,10)$. In a report, the internet addiction prevalence level among the adolescents has been announced about 9.72-11.06. Based on this report, almost $0.063 \%$ of the users are younger than 24 years old (11). Also in terms of gender, some studies revealed that women are more addicted to the internet than men (12). Amichai-Hamburger \& Ben-Artezi suggested that the students who are excessively internet dependent feel lonely psychologically (13). In a research on 18-72 year old Australian women $\&$ men, it has been showed that there is a negative meaningful relationship between psychoneurosis \& IA and a negative significant relationship between extroversion \& IA (14).

Cao et al. \& Yen et al. compared the psychological
\& social characteristics of the students using the internet excessively versus the other college goers. Their study drawn results indicated that the depression, anxiety, suicidal ideas, hyperactivity, phobia, social fear, aggression, antisocial violence \& behaviors in the students addicted to IA were higher than those of the other ones (6-15). The internet addiction can leave various pathologies on the individuals such as the psychological (anxiety, depression \& loneliness), physical (sleep \& diet disorders), family (reduced family relationships, the gap between family members), occupational ones (decreasing work efficiency) and educational drop-out $(16,17)$. However, studying the background \& previous research cases imply that the internet addiction has relationship with many field $\&$ personality variables. Considering this matter that the students get familiar with the modern technology and computer science $\&$ have more chance to use the internet, but in case of excessive use, the probability of being afflicted to addiction goes up in them and it may result in some undesirable effects on their physical $\&$ mental health and academic achievement. Thus the current study has been designed and implemented pursuing the goal to determine the internet addiction in the students studying at Islamic Azad University in Sari.

\section{Materials and Methods}

This is a descriptive research. In this study, the statistical community consists of all students of Islamic Azad University located in Sari. According to the latest university announced data \& statistics, the total number of the students busy studying is 7558 . In the present study, 261 individuals have been selected through random stratified sampling method out of the students busy studying in 2012-2013 (all ethical considerations have been followed in executing the study \& filling in the questionnaires and acquiring the required permit from the research council \& keeping the subjects' answers confidential \& analyzing the data statistically). The statistical sample has been determined based on sample size determination table from the statistical community size or Korjesi-Morgan 
table (18). Two questionnaires have been applied to gather data: 1) the demographic characteristics including age, gender and etc.; 2) The internet addiction test.

The IA test has been developed \& validated by Young. This scale is a 20-item self-evaluation scale based on Likert rating for measuring the internet addiction. Its rating is this way "Always (5), Often (4), usually (3), Sometimes (2), Rarely (1) and Never (0)". This test scores range from 0 to 100 . The more a person's score, the more his/her dependency on the internet. The internet addiction level has been divided into 4 classes based on the scores:

-The scores 0-19- normal

-The scores 20-49- mild

-The scores 50-79-average

-The scores 80-100- severe

In this classic study, Young developed \& validated this popular \& reliable scale of the internet addiction and its content \& structure validity has been confirmed. In the current research, the test reliability as $91 \%$ has been estimated using Alpha-Cronbach for whole sample (12). In Iran, the IA questionnaire has been translated and standardized and has an acceptable reliability \& validity (4). In Korea, Alpha-Cronbach more than $90 \%$ has been obtained for this test (9). To analyze the data, the descriptive statistics including: the estimation of $\%$, mean, standard deviation, table codification \& the inferential statistics including variance analysis have been employed.

\section{Results}

In this research, the students had mean age 24.3 and the standard deviation as 3.7. The male students were $150(57.47 \%)$ and 111 female $(42.52 \%)$, the single ones $220(84.29 \%)$ and the married ones $34(13.20 \%)$, 7 persons $(2.68 \%)$ were widowed. In terms of education, the highest number were bachelor holders as $200(76.62 \%)$ and the lowest were $\mathrm{PhD}$ holders as $12(4.59 \%)$. The results indicated that regarding the prevalence of the internet addiction, $82 \%$ were in mild, $0.4 \%$ normal \& $17.2 \%$ severe range (table 1 ).
Table 1. the absolute $\&$ relative frequency distribution of Saribranch Students IA

\begin{tabular}{lcc}
\hline No. $(\%)$ & $\begin{array}{c}\text { Statistical index of } \\
\text { Options }\end{array}$ & addiction level \\
\hline $1(0.4)$ & $0-19$ & normal \\
$214(82)$ & $20-49$ & mild \\
$45(17.2)$ & $49-79$ & average \\
$1(0.4)$ & $80-100$ & severe \\
$261(100)=$ sum & & \\
\hline
\end{tabular}

By ANOVA test, a meaningful difference has been achieved between age $\&$ IA in the students $(p=0.0006$ and $\mathrm{f}=1.054$ ). The study findings suggested that the internet addiction in the male students is higher than that in the female ones and it is statistically significant $(p=0.001$ and $t=4.267)$.

Table 2. \% distribution \& mean internet use per week

\begin{tabular}{lcc}
\hline No. (\%) & Mean (S.D) & $\begin{array}{c}\text { Statistical index of } \\
\text { use level }\end{array}$ \\
\hline $177(67.81)$ & $32.64(11.33)$ & $0-5 \mathrm{~h}$ \\
$46(17.62)$ & $39.63(13.26)$ & $6-10 \mathrm{~h}$ \\
$21(8.4)$ & $46.8571(12.79)$ & $11-15 \mathrm{~h}$ \\
$17(6.51)$ & $52.76(14.45)$ & $15 \mathrm{~h}$ and more \\
$261(100)$ & $36.33(13.43)$ & Total \\
\hline
\end{tabular}

Also the results denoted that the mean IA among the students using the internet 0-5 hours /week differs from those using it for $6-10 \mathrm{~h}, 11-15 \mathrm{~h}$ and $15 \mathrm{~h}$ or more (table 2). Besides, via ANOVA test, we conclude that the internet addiction in the students is meaningful based on internet use level ( $\mathrm{p}=0.001$ and $\mathrm{f}=22.655)$.

\section{Discussion}

The study results suggested that among the university students, $82 \%$ were in mild, $0.4 \%$ in normal, $17.2 \%$ in average \& $0.4 \%$ in severe internet addiction range. The Youth Internet Network Development Association of China in a report announced the internet addiction among the adolescents as about 9.2-11.06 \%( 11). In a study, it has been demonstrated that $14 \%$ students are addicted to the internet (19). Although, in the present research, it seems that IA has been announced in the average to severe range as $17.2 \%$. It seems this gap 
is the result of measurement tool, sample number $\&$ computer accessibility.

This study result is consistent with those of the other studies conducted by Yellowlees (7). These researchers mentioned that as the result of the excessive \& morbidful use of the internet, the students' psychological health goes to pot. They discovered that the students using the internet excessively \& pathologically displayed more psychological \& pathological disorders compared with those lacking such experience. The study derived findings imply that the internet addiction in boy students in higher than that among the girls. However, the study result about the internet addiction prevalence among the students suggested that $52.4 \%$ girls \& $47.6 \%$ boys suffer from IA (12).

In this field, Cao et al., Ghasemzade et al., Vizeshfar, Yellowlees et al., Griffiths, Stefanescu et al. pointed out the gender differences in this field $(15,10,7,5,20$, 21). The other researchers in their studies showed that the internet addiction level in women is less than that in men $(8,12)$. This difference in drawing conclusion can be attributed to sample size, sampling tool, the sample number and the internet accessibility among the users. It seems that the boy students have higher IA compared to the girls. However, the current research has been similar to the other studies performed worldwide revealing that the students suffering from IA have poor social communications \& psychological health .They have fear, anxiety, depression, aggression, loneliness, lack of identity, social anxiety and other morbidity symptoms pathologically and have poor social \& coping skills, these individuals prefer computer \& internet based communication to the social ones and have fewer social relations with self, friends, peers, family, spouse and people. Plus the present research findings indicated that the more the students deal with the internet $\&$ use it more, the higher their addiction level. In this regard, the studies by Cao et al., Yen et al., and Ghasemzade et al. have denoted that the increase in the internet working experiences accompanies with reduced psychological health \& increased computer addiction $(15,6,21)$. Maybe we can state that in the modern world, the internet \& computer technology are considered as the most effective tool provided that through presenting appropriate training \& strategies, it is used sufficiently for meeting needs not to the extent that it paralyzes people's physical \& mental health. Thus it can be stated that the internet addiction has drawn the attention of the researches in psychology, psychiatry, sociology \& the other scientific disciplines in the recent years and it is a nuisance seen in various societies and cultures and has influenced differently all people in different age brackets and genders (22). As the research findings display, we conclude that the internet addiction (IA) in the students ranges from mild to severe and this important difference from the other cultures can be attributed to this reason that using the internet isn't easy \& accessible everywhere $\&$ every time in our country \& region. Focusing on the health \& therapeutic considerations seems essential. Of the limitations the present study has is studying Sari-based Islamic Azad University students; thus it is recommended that in the subsequent studies, the other universities with higher sample sizes be analyzed in order to generalize the results with more confidence.

\section{Conflict of interests}

The authors declare that they have no competing interests.

\section{Author's contributions}

R. Hasanzadeh was involved in the acquisition of data, analysis/interpretation of data drafting of the manuscript and review of content. G. Mahmoodi was involved in the study conception, design and material support. M. Bagheri- Nesami was involved in the critical revisions for important intellectual content and review off content. J. Heydari was involved in the study conception, design and analysis/interpretation of data, critical revision for important intellectual content and review of content. 


\section{Acknowledgment}

We thank azad university (sari branch) and all students who help us to collect data.

\section{References}

1. Mirzaeean B, Baezzat F, khapour N. Internet addiction among college students and their effects on mental health. Journal of Information and Communication Technologies in Educational Sciences. 2011; 1(5): 160141 (Persian).

2. Gonzalez NA. Internet addiction disorder and its relation to impulse control. (thesis) USA: Texas University, Collage of Psychology; 2008.

3. Yang SC, Tung C J. Comparison of internet addicts and non-addicted taiwanese high school. Comput Hum Behav. 2007; 23(1): 79-96.

4. Alavi SS, Eslami M, Maracy MR, Najafi M, Jannatifard F , Rezapour H. Psychometric characteristics of young internet addiction test in university students. Journal of Behavioral Sciences. 2010; 4(3): 183-189 (Persian).

5. Stefanescu C, Chele G, Chirita R, Chirita V, Ilinca M. The relationship between development identity and internet addiction. European Psychiatry. 2007; 22(1): 200.

6. Yen JY, Ko CH, Yen CF, Wu HY, Yang MJ. The comorbid psychiatric symptoms of internet addiction: attention deficit and hyperactivity disorder (ADHD), depression, social phobia, and hostility. J Adolesc Health. 2007; 41(1): 93-98

7. Yellowlees PM, Marks SH. Problematic internet use or internet addiction? Comput Hum Behav . 2005; 23 (3): 1447-1453.

8. Li SM, Chung TM. Internet function and internet addictive behavior. Comput Hum Behav. 2006, 22(6): 1067-1071.

9. Kim K, Ryu E, Chon, MY, Yuen EJ, Choi SY, Seo JS, Nam BW. Internet addiction in Korean adolescents and its relation to depression and suicidal ideation: A questionnaire survey. Int J Nurs Stud. 2006; 43(2): 185-192.

10. Griffiths M. Internet abuse in the workplace: issues and concerns for employers and employment counselors.
Journal of Employment Counseling. 2003; 40(2): 87-96.

11. Cui L J, Zhao X, Wu ZM, Xu ZH. A research on the effects of internet addiction on adolescent's social development. Psychological Science. 2006; 1: 34-36.

12. Hosseini Beheshtian SM . Comparison of internet addiction between girl and boy student of universities of Tehran. Pazhuheshname-ye Zanan (Womans Studies). 2011; 2(2): 23-42 (Persian).

13. Amichai-Hamburger Y, Ben-Artzi E. Loneliness and internet use. Computer in Human Behavior. 2003; 19(1): 71-80.

14. Hardie E, Tee MY. Excessive internet use: the role of personality, loneliness and social support networks in Internet addiction. Australian Journal of Emerging Technologies and Society. 2007; 5(1): 34-47.

15. Cao F, Su L, Liu T, Gao X. The relationship between impulsivity and internet addiction: in a sample of Chinese adolescents. Eur Psychiatry. 2007; 22(7): 466-471.

16. Carr, Nicholas. The shallows: what the internet is doing to our brains. New York: W.W.Norton \& Company; 2011.

17. Flisher C. Getting plugged in: an overview of internet addiction. J Pediatr Child Health. 2010; 46(10): 557559. PMID: 20979347.

18. Naderi E, Seif Naraghi M. Research methods and how to assess humanities (with an emphasis on educational sciences). 5th ed. Tehran: Arasbaran publication; 2012 ( Persian).

19. Morahan-Martin J, Schumacher P. Loneliness and social uses of the internet. Computers in Human Behavior. 2003; 19(6): 659-671.

20. Ghasemzade L, Shahriary M, Moradi AR. Study rate of internet addiction prevalence in girls , comparing addict girls and unaddicted girls based on isolation, self esteem, social skills variables. Current Psychology. 2007; 1(3): 32-38 ( Persian).

21. Vizeshfar F. Studying rate of internet addiction among coffee net users in Lar city. Journal of Fundamentals of Mental Health . 2005; 7(25-26): 27-33.

22. Moeedfar S, Habbibpoor E, Getabi K, Ganji A. Studying internet addiction between adolescents and youth between 15-25 years old in Tehran University. Global Media Journal. 2007; 2(2): 38-55 (Persian). 